\title{
Measuring Poverty Level of Households by Using Fuzzy Logic
}

\author{
Hakan Pabuçcu \\ Department of Business Administration, Bayburt University, Turkey
}

Copyright@2017 by authors, all rights reserved. Authors agree that this article remains permanently open access under the terms of the Creative Commons Attribution License 4.0 International License

\begin{abstract}
Poverty is general scarcity or the state of one who lacks a certain amount of material possessions or money. Poverty is a multifaceted concept, which includes social, economic, and political elements. Poverty level can be calculated for households as well as for countries. United Nations developed a methodology to calculate the advanced poverty index for countries. The main purpose of this study is primarily to determine the determinants of poverty by conducting a strong literature survey and examining the United Nations methodology. By using the determinants of poverty, it is planned to calculate the poverty index and classify the households with an approach based on fuzzy logic. The applied methodology contains the weighting of the determinants of poverty by using fuzzy logic membership functions and the calculation of the poverty index of households. The weighting process of the determinants has recognized by taking the opinions of the expert academicians in the field of poverty. It is also considered to categorize the households, according to the level of poverty. For this purpose, it is determined a sample consisting of 120 households in Bayburt province. As a result of the analysis, it is aimed to examine the effect of factors determined the poverty and also provide suggestions to the researchers and policy makers.
\end{abstract}

Keywords Measuring Poverty, Fuzzy Logic,
Households

\section{Introduction}

Poverty is defined as the situation in which minimum living conditions have not been achieved according to the definition of the World Bank. Until recently, poverty has been calculated as a one-dimensional index using country or person income. However, some studies show that poverty is not simply a concept that can be calculated only on the basis of income. There are many factors affecting poverty, and a multidimensional poverty measurement methodology has emerged. Income inequality and development, which are regarded as a similar measure beside poverty, are also seen today as an important problem of the whole world. In order for developing countries such as Turkey to be able to fulfill the standards of the developed countries, it is necessary to equitably distribute the available resources among the households and to provide income equality[4]. Many methods have been developed to measure poverty in this way. In the past periods, only income-based approaches have been taken as the basis, and nowadays, multidimensional calculation methods are at the forefront and poverty is tried to be examined with all its dimensions. It was for the first time emphasized that poverty is a multidimensional concept with the report published by the UN in 2010 and a new calculation method (index) has been proposed. Poverty index is collected under three main dimensions as health, education and living standards as well as in the human development index. The most important reason for calculating the poverty index is to identify poverty-stricken countries and households and to allocate resources effectively.

Recent interest in poverty measurement has increased significantly with the ease of access to datasets. The social determinants must be very well identified while measuring poverty and the answer to the question of which the poor are should be sought. However, since poverty differs according to time and space, a question of research emerges, such as how to measure the level of poverty in society. Traditional poverty measurement studies are generally based on income-expenditure and on two-valued logic, and it is widely accepted that fuzzy logic may be an important measurement approach for solving such a problem in recent times. From this point, it is decided to use fuzzy logic as a measurement method in this study because of the ambiguity of poverty concept.

The purpose of this study is to investigate the determinants of household poverty, to calculate a multidimensional poverty index using these determinants and to reveal poverty report at the household level of the province by using a sample from Bayburt. As a result of the analyzes it is aimed to classify the Bayburt province households according to 
their poverty grades and to identify the major deficiencies in the subject.

The study will reveal the missing aspects in practice and will enable the application of this calculation for the whole of Turkey with a wider and more representative sample. In addition, the method applied in this study seems to be important in that it includes multidimensional nature of poverty and the uncertainty of human thinking with the help of linguistic expressions-variables.

In the course of the work, a summary of the literature survey and the methods used for the studies on poverty and poverty measurement will be presented. Finally, the results of the analysis on the selected sample in Bayburt will be shared and comments and suggestions will be made.

\section{Literature Survey}

In this study, the concept of poverty was addressed at the household level and examined it with a fuzzy logic based approach. The studies applied to alternative calculation methods on poverty are examined below.

Social quality of life is a very important determinant for countries and individuals. At this point, poverty is one of the most important of these, along with many measures in the literature. The debate over the structure, definition and measurement of poverty has been going on for many years. Studies have shown that poverty differs according to time and space and needs to be examined dynamically. [5] has contributed a different dimension to the shaping of literature as a revolutionary research on poverty and poverty measurement. The studies are concentrated in a two-step process as the definition of the poor and the calculation of the poverty index. Many traditional approaches have been applied on the basis of income and expenditure [6]. However, while income and expenditures are crucial for poverty measurement, the monetary approach is not always sufficient for measuring a multidimensional concept of poverty[7].

[8] suggested a linguistic description of poverty. He argued that a household should be below a minimum threshold in order for a household to be considered completely poor, and should be above a maximum threshold for not being considered completely poor. [3] applied two different methods of poverty measurement using grouped data sets, based on simple interpolation and parametric Lorenz curves. Categorized the amount of income per person per month into 13 classes and analyzed it. So it was calculated a one-dimensional poverty index. [9] examined the extent of poverty and the measurement of poverty in detail. The politics of the World Bank, which is thought to have done important work at the point of alleviating poverty, has been debated.

At the point of poverty alleviation and efficient distribution of resources, it was emphasized and suggested that policies related to economic growth, human investment, participation and environment, economic equilibrium and
World Bank debts should be developed.

[10] emphasized that the poverty and income inequality in the world significantly increased due to the neo-liberal economic policies and globalization process. Parallel to this, it is also discussed, the increase in poverty and income inequality after 1980 and the effects of poverty alleviation policies in Turkey. In the study, the poverty situation was investigated in detail within the framework of Turkey's economic and social transformation. In [4], income inequality and poverty have been expressed as a very important problem for Turkey. It is also noted that there has been no significant improvement in poverty since the 1960s when Turkey was compared with developed countries in a disadvantageous position. It is stated that political power in Turkey does not show the necessary importance for income inequality and social policy to reduce poverty. [11] tried to investigate the factors determining the poverty of the households according to consumption expenditures and income between 2002-2006. As a result of the econometric analyzes, the age and the level of education of the householder increases, the risk of impoverishment decreases. It was also found that the rate of poverty in rural areas is higher and that there is little improvement from 2002 to 2006. A multidimensional poverty measurement methodology was developed using traditional methods in [12] and tested on the US and Indonesia. The first step in the method is to test which class of household is included, and the second stage is the determination of the poverty levels of the household. Income, health, insurance and schooling dimensions were used for the test of the method.

[13] stated that there are differences between countries in the formation of poverty trap and the most important differences are factors such as having low confidence level of individuals, being citizens at a limited level, disadvantaged environments, social exclusion problem and income inequality. For Turkey in the study, it is examined that the management is in the hands of a select group and that illegal organizations cause poverty. The results have been examined economically and socially. [14] emphasized the development of multidimensional measurement methodologies instead of income-based approaches to poverty measurement. In the study, it was expressed that a multi-dimensional index would be an effective way to monitor the situation of the 27 member states of the European Union (EU). Moving from the EU 2020 poverty targets, axioms have been developed for a new calculation method and assessments have been made for the EU.

Fuzzy logic is the whole of mathematical methods introduced by [15] and used in many fields such as poverty measurement in economics literature. All of the measurements based on fuzzy logic on poverty are calculated by moving from [15]. [16] it was examined the fuzzy measures of poverty and the philosophical foundations of multidimensionality. [17], [18] tried to define poverty by using fuzzy set theory and membership functions in their work, and found in the context of Italy. [19] also compared 
the results of multi-dimensional poverty measurement based on fuzzy logic with different empirical studies. [20]-[22] have proposed methods for calculating the human development index and quality of life index built on fuzzy logic based. [7] developed a multidimensional poverty index calculation method based on the calibration of fuzzy set membership functions by the expert opinions.

\section{Fuzzy Logic}

Fuzzy logic calculations can be seen as a step-by-step process. First, the linguistic expressions-variables are used according to the model to be applied, or the membership grades are calculated by means of the corresponding membership functions of the data obtained using the secondary data sources. This process is called the fuzzifying process. The arithmetic operations that are required in the future are performed using the relevant operators. Obtained fuzzy results are then defuzzified by using the defuzzying methods, and normalization is performed if necessary. The linguistic expressions and their fuzzy representation to be used, the membership functions and the defuzzifying methods vary according to the problems. Some basic concepts and definitions of calculation process and fuzzy logic are as follows [7].

$>\quad \check{r}$ is a fuzzy number defined on a set of real number $(\mathbb{R})$ characterized by a membership function $\mu_{\breve{r}}: \mathbb{R} \rightarrow[0,1]$ has some features as follows:

1. $\mu_{\check{r}}$ is upper semi-continuous

2. $\check{r}$ is a convex fuzzy set: $\mu_{\breve{r}}(\lambda x+(1-\lambda) y) \geq$ $\min \left\{\mu_{\check{r}}(x), \mu_{\check{r}}(y)\right\}, \forall x, y \in \mathbb{R}, \lambda \in[0,1]$;

3. $\check{r}$ is normal: $\exists x_{0} \in \mathbb{R}, \mu_{\check{r}}\left(x_{0}\right)=1$

$>\tilde{A}=\left(a_{1}, a_{2}, a_{3}\right)$ is a fuzzy number, called triangular and its memberhip function is as follows (in Eq 1):

$$
\mu_{A}(x)=\left\{\begin{array}{c}
\frac{x-a_{1}}{a_{2}-a_{1}}, a_{1} \leq x \leq a_{2}, \\
\frac{a_{3}-x}{a_{3}-a_{2}}, a_{2} \leq x \leq a_{3,} \\
0, \text { otherwise }
\end{array}\right.
$$

The basic operators used for triangular fuzzy numbers (TFN) are as follows:

$\tilde{A}=\left(a_{1}, a_{2}, a_{3}\right)$ and $\tilde{B}=\left(b_{1}, b_{2}, b_{3}\right)$ are two TFN.

1. $\tilde{A} \oplus \tilde{B}=\left(a_{1}+b_{1}, a_{2}+b_{2}, a_{3}+b_{3}\right)$ (Aggregation)

2. $\tilde{A} \otimes \tilde{B}=\left(a_{1} b_{1}, a_{2} b_{2}, a_{3} b_{3}\right)$ (Product)

3. $c \oplus \tilde{B}=\left(c b_{1}, c b_{2}, c b_{3}\right)$ (product of a scalar)

The defuzzification is simply the period during which the fuzzy control movements defined in the output universal set are mapped to the non-fuzzy (crisp) control movements. The main purpose of the defuzzification strategies is to be able to produce a non-fuzzy control mechanism that can best represent the probability distribution of a system obtained by fuzzy control mechanisms [23], [24]. While it is not a systematic approach to select the defuzzification strategy, a method should be chosen according to the problem structure [25]. Defuzzification methods that can be applied to different fuzzy clusters are discussed in [26]. From this point, the signed distance method [27] has been preferred in this study due to its frequency and ease of use. $\tilde{A}=\left(a_{1}, a_{2}, a_{3}\right)$ is a TFN and the defuzzification process is performed according to the distance method by using Eq. (2).

$$
d(\tilde{A})=1 / 4\left(a_{1}+2 a_{2}+a_{3}\right)
$$

Normalization of the membership value of each category of each variable after defuzzification has been performed; by dividing the value calculated for each class by the maximum value of the respective classes. For example, for a five-categorical variable, each of the $d_{i}(A)$ values calculated according to equation 2 is divided by the $\max \left(d_{i}(A)\right)$ value. Thus, the normalization process is performed so that the greatest membership value is ' 1 '. In Table 6 , the normalization of each category is done by this method.

$>$ The structure of some of the variables used in the decision-making process can be represented using linguistic expressions, since they are difficult to express numerically. The linguistic variable is a function that has a linguistic expressions such as 'very good', 'good', 'medium', 'bad' and 'very bad'. These components can be in the form of triangular, trapezoidal or other fuzzy numbers. Table 1 presents the linguistic variable that can represent the housing condition in which a family lives.

Table 1. Linguistic Expressions and fuzzy representations

\begin{tabular}{|c|c|}
\hline Housing condition & Fuzzy representations \\
\hline Very bad (VB) & $(0,0,0.2)$ \\
Bad (B) & $(0.2,0.3,0.4)$ \\
Medium (M) & $(0.4,0.5,0.6)$ \\
Good (G) & $(0.6,0.7,0.8)$ \\
Very good (VG) & $(0.8,1,1)$ \\
\hline
\end{tabular}

\section{Empirical Methodology}

Poverty is a very important phenomenon in the economic literature. For this reason, a number of studies have been conducted on the determinants of poverty and its measurement. Multidimensional poverty calculations are of interest rather than a reduced poverty estimate to a single dimension.

Determinants of poverty were investigated by conducting a comprehensive literature review and by the UN multidimensional poverty index methodology. For household poverty measurement, it was used methodology proposed by [7] and [15]. Let $H_{1}, H_{2}, \ldots, H_{n}$ be n households, $E_{1}, E_{2}, \ldots, E_{m}$ be m experts and $V_{1}, V_{2}, \ldots, V_{P}$ be $\mathrm{p}$ variables. Variables can be either crisp values or fuzzy numbers.

Fuzzy variables were grouped according to their properties and the membership grades were assigned to each group calibrating the functions by 3 experts. For example, the $V_{1}$ variable is classified as five different groups: very bad (VB), bad (B), medium (M), good (G) and very good (VG). The author and experts have set membership grade for 
the measurement categories of variables using different linguistic expressions and the TFN of those linguistic expressions. The choice of experts at this point is seen as a very important problem. For that reason, 3 academicians who have made important academic studies in the field of poverty were selected as experts in the study and the evaluations were used within the scope of the analysis. Experts' evaluations were converted to a TFN by using the fuzzy representation such as in Table 1 . It is used the 'minimum', 'average' and 'total' operators to calculate the aggregated TFN to combine the experts opinions. Finally, it is applied the defuzzifying process using the signed distance method to obtain the crisp values.

In multidimensional poverty measurement, the level of influence of the determined factors on poverty is a very important problem. While this question is not a definite and clear answer, many suggestions are presented in many studies. In this study, the selected variables were compared and weighted using the linguistic expression and represented TFN determined by the authors and experts. The general form of the linguistic expressions and evaluation matrix used is shown in Table 2.

Table 2. Variable Evaluation Matrix (for Weighting)

\begin{tabular}{|c|c|c|c|}
\hline Linguistic expressions & Exp. 1 & Exp. 2 & Exp. 3 \\
\hline Very low important (VLI) & $\breve{\mathrm{W}}_{1}^{1}$ & $\breve{\mathrm{W}}_{2}^{1}$ & $\breve{\mathrm{W}}_{3}^{1}$ \\
low important (LI) & $\breve{\mathrm{W}}_{1}^{2}$ & $\breve{\mathrm{w}}_{2}^{2}$ & $\breve{\mathrm{W}}_{3}^{2}$ \\
important (I) & $\breve{\mathrm{W}}_{1}^{3}$ & $\breve{\mathrm{w}}_{2}^{3}$ & $\breve{\mathrm{W}}_{3}^{3}$ \\
Very important (VI) & $\breve{\mathrm{W}}_{1}^{4}$ & $\breve{\mathrm{w}}_{2}^{4}$ & $\breve{\mathrm{W}}_{3}^{4}$ \\
Very very important (VVI) & $\breve{\mathrm{w}}_{1}^{5}$ & $\breve{\mathrm{w}}_{2}^{5}$ & $\breve{\mathrm{w}}_{3}^{5}$ \\
\hline
\end{tabular}

Here, $\breve{w}_{i}^{j}=w_{i 1}^{j}, w_{i 2}^{j}, w_{i 3}^{j}$ is a TFN. For each variable $V_{j}(j=1,2, \ldots n)$ linguistic expressions were used to evaluate 3 experts in the form of $\{\mathrm{LI}, \mathrm{LI}, . . ., \mathrm{I}\}$. Linguistic expressions were transformed into TFN and an evaluation matrix was formed. The sum of experts' evaluations for each variable is calculated by the $\widetilde{w}_{A j}^{1}=\left(w_{A j}^{1}, w_{A j}^{2}, w_{A j}^{3}\right)$ formula. Here;

$$
\left\{\begin{array}{c}
w_{A j}^{1}=\min _{1 \leq s \leq 5}\left\{w_{11}^{s}, w_{21}^{s}, w_{31}^{s}\right\} \\
w_{A j}^{2}=\sum_{i=1}^{3} \frac{w_{i 2}^{s}}{p}, 1 \leq s \leq 5, \\
w_{A j}^{3}=\max _{1 \leq s \leq 5}\left\{w_{13}^{s}, w_{23}^{s}, w_{33}^{s}\right\} .
\end{array}\right.
$$

Variable weighting process is described in Table 3.
For the Bayburt province poverty report, 120 households were identified by stratified sampling method. The average household size is calculated as 4.2. In Bayburt center, firstly all neighborhoods were identified and household number statistics were collected. Data were collected in proportion to the household size of the neighborhoods. The sample rate was approximately 2.1 percent. The variables used (Table 4) were determined by a comprehensive literature review and the UN poverty index calculation methodology. Since the poverty index calculated for the countries is calculated over the households, a large part of the variables used are common variables. The summary description of the variables is as follows.

Table 4. Variables and Definitions

\begin{tabular}{|c|c|c|}
\hline Variables & Code & $\begin{array}{c}\text { Number of } \\
\text { category }\end{array}$ \\
\hline Housing condition & $V_{1}$ & 5 \\
Educational status & $V_{2}$ & 7 \\
Monthly income & $V_{3}$ & 7 \\
Number of dependent person & $V_{4}$ & 6 \\
Special vulnerability & $V_{5}$ & 2 \\
Food security & $V_{6}$ & 5 \\
Cooking fuel & $V_{7}$ & 2 \\
Internet access & $V_{8}$ & 2 \\
Use of transportation vehicle & $V_{9}$ & 2 \\
\hline
\end{tabular}

Housing condition: It is an indicator of the quality of the physical environment inhabited by the households. It is classified as 'very bad' (VB), 'bad' (B), 'medium' (M), 'good' (G) and 'very good' (VG).

Educational status: The educational level of the individual with the highest level of education in the household. It is expressed as no education (NE), primary school (PE), junior high school (JHS), high school (HS), university (U), master degree (MD) and doctorate (D).

Monthly income: Represents the total income of the households living together. If the disabled person is in the family or benefits from social assistance for another reason, the related amount is included in the monthly income. The 1300-4800 Turkish Liras (TL) range is classified into seven categories.

Number of dependent person: It is classified into the categories 2-3-4-5-6 and more than 6 .

Special vulnerability: Indicates whether any member of households having a special vulnerability. If the answer is yes, it is represented as " 0 " and if it is no, it is represented as "1".

\section{Data Set}

Table 3. Weighting Operations

\begin{tabular}{|c|c|c|c|}
\hline $\operatorname{Variable}\left(\boldsymbol{V}_{\boldsymbol{j}}\right)$ & $\begin{array}{l}\text { According to expert evaluations, aggregated TFN } \\
\qquad \breve{\boldsymbol{w}}_{A j}^{1}=\left(\boldsymbol{w}_{A j}^{1}, \boldsymbol{w}_{A j}^{2}, \boldsymbol{w}_{A j}^{3}\right)\end{array}$ & $\begin{array}{c}\text { Defuzzified value } \\
\boldsymbol{d}\left(\breve{\boldsymbol{w}}_{A j}^{1}\right)=\frac{1}{\mathbf{4}}\left(\boldsymbol{w}_{A j}^{1}+2 \boldsymbol{w}_{A j}^{2}+\boldsymbol{w}_{A j}^{3}\right)\end{array}$ & $\begin{array}{l}\text { Normalized value (Actual weight) } \\
\qquad \boldsymbol{w}_{\boldsymbol{j}}=\frac{\boldsymbol{d}\left(\boldsymbol{w}_{A j}\right)}{\sum_{j=\mathbf{1}}^{n} \boldsymbol{d}\left(\boldsymbol{w}_{A j}\right)}\end{array}$ \\
\hline $\begin{array}{l}V_{1} \\
V_{2} \\
V_{3} \\
\ldots \\
V_{n}\end{array}$ & $\begin{array}{c}\breve{W}_{1}^{1} \\
\breve{w}_{1}^{2} \\
\breve{w}_{1}^{3} \\
\ldots \\
\breve{w}_{1}^{n}\end{array}$ & $\begin{array}{c}\breve{\mathrm{W}}_{2}^{1} \\
\breve{\mathrm{w}}_{2}^{2} \\
\breve{\mathrm{w}}_{2}^{3} \\
\ldots \\
\breve{\mathrm{W}}_{2}^{\mathrm{n}}\end{array}$ & $\begin{array}{c}\breve{\mathrm{w}}_{3}^{1} \\
\breve{\mathrm{w}}_{3}^{2} \\
\breve{\mathrm{w}}_{3}^{3} \\
\ldots \\
\breve{\mathrm{w}}_{3}^{\mathrm{n}}\end{array}$ \\
\hline
\end{tabular}


Food security: According to the Food and Agriculture Organization (FAO), food security is defined as having adequate physical, social and economic access to adequate and safe food that meets everyone's nutritional needs and preferences for an active and healthy lifestyle. The assessment was done as very bad (VB), bad (B), medium (M), good (G) and very good (VG).

Cooking fuel: Using 'dirty' cooking fuel (dung, wood or charcoal). If the answer is yes, it is represented as " 0 " and if it is no, it is represented as "1".

Internet access: If households have an internet access, it represented " 1 ", otherwise " 0 ".

Use of transportation vehicle: Having at least one asset related to mobility (bike, motorbike, car, truck etc.).

\section{Empirical Results}

Sample calculation tables of 5 households will be given in order to understand the calculation steps of the study. The data for the 5 households are shown in Table 5.
According to Table 5, it is possible to reach information such that the housing conditions of the first household are 'good', the number of dependent persons is '2', and access to healthy food and drinking water so food security is 'very bad'. At the direction of the evaluations of author and experts, scales were constructed using TFN. The scale used by each expert is different. The membership grades calculated for each variable category are given in Table 6. Careful attention has been given to the fact that the lower and upper limit values of the categories are not included in the other group when the educational status is evaluated by the changing experts. This is important because a household is not educated and at the same time has no primary school graduation while the membership level of each group is calculated. The values given as normalize values are the membership values of the categories used. By using these values, households' data are converted into relevant membership grades and prepared for analysis.

Table 5. Household Data Matrix

\begin{tabular}{|c|c|c|c|c|c|c|c|c|c|}
\hline House holds & $V_{1}$ & $V_{2}$ & $V_{3}$ & $V_{4}$ & $V_{5}$ & $V_{6}$ & $V_{7}$ & $V_{8}$ & $V_{9}$ \\
\hline$H_{1}$ & $\mathrm{G}$ & $\mathrm{U}$ & 7 & 2 & 1 & $\mathrm{VB}$ & 1 & 1 & 1 \\
$H_{2}$ & $\mathrm{G}$ & $\mathrm{MD}$ & 7 & 2 & 1 & $\mathrm{M}$ & 1 & 1 & 1 \\
$H_{3}$ & $\mathrm{M}$ & $\mathrm{NE}$ & 2 & 6 & 1 & $\mathrm{M}$ & 0 & 0 & 1 \\
$H_{4}$ & $\mathrm{G}$ & $\mathrm{HS}$ & 2 & 5 & 1 & $\mathrm{G}$ & 1 & 1 & 0 \\
$H_{5}$ & $\mathrm{M}$ & $\mathrm{PS}$ & 1 & 4 & 0 & $\mathrm{M}$ & 0 & 0 & 0 \\
\hline
\end{tabular}

Table 6. Membership Grades Calculated for Variable Categories

\begin{tabular}{|c|c|c|c|c|c|c|c|}
\hline Variable & Category & Exp. 1 & Exp. 2 & Exp. 3 & Aggregated val. & Defuz. Val. & $\begin{array}{l}\text { Norm. } \\
\text { Val.. }\end{array}$ \\
\hline \multirow{5}{*}{$V_{1}$} & VB & $(0,0,0.2)$ & $(0,0,0.15)$ & $(0.05,0.2,0.25)$ & $(0,0.07,0.25)$ & 0.10 & 0.11 \\
\hline & B & $(0.2,0.3,0.4)$ & $(0.1,0.25,0.35)$ & $(0.25,0.4,0.45)$ & $(0.1,0.32,0.45)$ & 0.30 & 0.33 \\
\hline & M & $(0.4,0.5,0.6)$ & $(0.3,0.45,0.55)$ & $(0.45,0.6,0.65)$ & $(0.3,0.52,0.65)$ & 0.50 & 0.55 \\
\hline & G & $(0.6,0.7,0.8)$ & $(0.5,0.65,0.75)$ & $(0.65,0.8,0.85)$ & $(0.5,0.72,0.85)$ & 0.70 & 0.77 \\
\hline & VG & $(0.8,1,1)$ & $(0.7,0.85,1)$ & $(0.85,1,1)$ & $(0.7,0.95,1)$ & 0.90 & 1 \\
\hline \multirow{7}{*}{$V_{2}$} & $\mathrm{NE}$ & $(0,0.05,0.15)$ & $(0,0.07,0.15)$ & $(0.05,0.1,0.2)$ & $(0.0 .07,0.2)$ & 0.09 & 0.09 \\
\hline & $\mathrm{P}$ & $(0.15,0.2,0.3)$ & $(0.15,0.22,0.3)$ & $(0.2,0.5,0.35)$ & $(0.15,0.22,0.35)$ & 0.24 & 0.24 \\
\hline & JHS & $(0.3,0.35,0.45)$ & $(0.3,0.37,0.45)$ & $(0.35,0.4,0.5)$ & $(0.30,0.37,0.5)$ & 0.39 & 0.40 \\
\hline & HS & $(0.45,0.5,0.6)$ & $(0.45,0.52,0.6)$ & $(0.5,0.55,0.65)$ & $(0.45,0.52,0.65)$ & 0.54 & 0.55 \\
\hline & $\mathrm{U}$ & $(0.6,0.65,0.75)$ & $(0.6,0.67,0.75)$ & $(0.65,0.7,0.8)$ & $(0.60,0.67,0.8)$ & 0.69 & 0.70 \\
\hline & MD & $(0.75,0.8,0.9)$ & $(0.75,0.82,0.9)$ & $(0.8,0.85,0.95)$ & $(0.75,0.82,0.95)$ & 0.84 & 0.86 \\
\hline & $\mathrm{D}$ & $(0.9,1.1)$ & $(0.9,1.1)$ & $(0.95,1.1)$ & $(0.9,1.1)$ & 0.98 & 1 \\
\hline \multirow{7}{*}{$V_{3}$} & 1 & $(0.1,0.1,0.2)$ & $(0,0,0.17)$ & $(0,0,0.15)$ & $(0,0.03,0.2)$ & 0.07 & 0.07 \\
\hline & 2 & $(0.2,0.3,0.4)$ & $(0.09,0.17,0.26)$ & $(0.09,0.17,0.29)$ & $(0.09,0.21,0.4)$ & 0.23 & 0.24 \\
\hline & 3 & $(0.3,0.4,0.5)$ & $(0.22,0.29,0.4)$ & $(0.22,0.29,0.45)$ & $(0.22,0.33,0.5)$ & 0.34 & 0.36 \\
\hline & 4 & $(0.4,0.5,0.6)$ & $(0.32,0.44,0.6)$ & $(0.32,0.45,0.6)$ & $(0.32,0.46,0.6)$ & 0.46 & 0.48 \\
\hline & 5 & $(0.6,0.7,0.8)$ & $(0.47,0.63,0.79)$ & $(0.49,0.6,0.76)$ & $(0.47,0.64,0.8)$ & 0.64 & 0.67 \\
\hline & 6 & $(0.7,0.8,0.9)$ & $(0.68,0.83,0.91)$ & $(0.69,0.83,0.91)$ & $(0.68,0.82,0.91)$ & 0.81 & 0.84 \\
\hline & 7 & $(0.9,1.1)$ & $(0.83,1.1)$ & $(0.85,1.1)$ & $(0.83,1.1)$ & 0.96 & 1 \\
\hline \multirow{6}{*}{$V_{4}$} & $6+$ & $(0,0,0.2)$ & $(0,0.1,0.25)$ & $(0.1,0.15,0.25)$ & $(0,0.08,0.25)$ & 0.10 & 0.11 \\
\hline & 6 & $(0.2,0.3,0.4)$ & $(0.2,0.3,0.4)$ & $(0.25,0.3,0.4)$ & $(0.2,0.3,0.4)$ & 0.30 & 0.32 \\
\hline & 5 & $(0.35,0.45,0.55)$ & $(0.38,0.5,0.55)$ & $(0.40,0.45,0.55)$ & $(0.35,0.47,0.55)$ & 0.46 & 0.49 \\
\hline & 4 & $(0.5,0.6,0.68)$ & $(0.5,0.55,0.65)$ & $(0.55,0.6,0.7)$ & $(0.5,0.58,0.7)$ & 0.59 & 0.63 \\
\hline & 3 & $(0.65,0.76,0.85)$ & $(0.65,0.75,0.85)$ & $(0.7,0.75,0.85)$ & $(0.65,0.75,0.85)$ & 0.75 & 0.81 \\
\hline & 2 & $(0.85,1,1)$ & $(0.8,0.9,1)$ & $(0.85,1,1)$ & $(0.8,0.97,1)$ & 0.93 & 1 \\
\hline \multirow{5}{*}{$V_{6}$} & VB & $(0.05,0.15,0.3)$ & $(0.0 .1,0.2)$ & $(0.0,0.1)$ & $(0.0 .08,0.3)$ & 0.12 & 0.13 \\
\hline & B & $(0.25,0.35,0.5)$ & $(0.2,0.3,0.4)$ & $(0.1,0.25,0.4)$ & $(0.1,0.3,0.5)$ & 0.30 & 0.34 \\
\hline & M & $(0.45,0.55,0.7)$ & $(0.4,0.5,0.6)$ & $(0.3,0.45,0.6)$ & $(0.3,0.5,0.7)$ & 0.50 & 0.57 \\
\hline & G & $(0.65,0.75,0.9)$ & $(0.6,0.7,0.8)$ & $(0.5,0.65,0.8)$ & $(0.5,0.7,0.9)$ & 0.70 & 0.80 \\
\hline & VG & $(0.85,0.95,1)$ & $(0.8,0.9,1)$ & $(0.7,0.85,1)$ & $(0.7,0.9,1)$ & 0.88 & 1 \\
\hline
\end{tabular}


Table 5 was rearranged according to the membership grades calculated in Table 6, and the household variable value matrix (Table 7) was established.

To determine the extent to which variables influence poverty, relevant variables are weighted using expert assessments. At this stage, the author and experts evaluated the variables using linguistic expressions with different TFN represents. The scales used by the experts are presented in Table 8. The answers given by experts are linguistic expressions and they were converted by the author into TFN and weighted. The evaluations performed by the experts for the variables are shown in Table 9.
Table 10 shows that experts' evaluations of variables are converted using TFN. The evaluations of the experts were transformed into an aggregated value, and the final weights were calculated after the defuzzification and normalization processes. For example, $V_{1}$ (housing conditions) is calculated as the weight of the variable (0.13). The processes carried out here show that many factors must be taken into consideration in calculating poverty instead of an income-expenditure based approach is not sufficient. Table 10 shows that the income level of households affects poverty at the highest level (0.21), while some other variables have high coefficients. As Table 10 is generated, the calculation is performed in accordance with the steps described in Table 3.

Table 7. Household variable value matrix

\begin{tabular}{|c|c|c|c|c|c|c|c|c|c|}
\hline & \multicolumn{9}{|c|}{ Variables } \\
\hline Households & $V_{1}$ & $V_{2}$ & $V_{3}$ & $V_{4}$ & $V_{5}$ & $V_{6}$ & $V_{7}$ & $V_{8}$ & $V_{9}$ \\
\hline$H_{1}$ & 0,77 & 0,70 & 1 & 1 & 1 & 0,13 & 1 & 1 & 1 \\
$H_{2}$ & 0,77 & 0,86 & 1 & 1 & 1 & 0,57 & 1 & 1 & 1 \\
$H_{3}$ & 0,55 & 0,09 & 0,24 & 0,11 & 1 & 0,57 & 0 & 0 & 1 \\
$H_{4}$ & 0,77 & 0,55 & 0,24 & 0,49 & 1 & 0,80 & 1 & 1 & 0 \\
$H_{5}$ & 0,55 & 0,24 & 0,07 & 0,63 & 0 & 0,57 & 0 & 0 & 0 \\
\hline
\end{tabular}

Table 8. Linguistic Expressions and Fuzzy Numbers

\begin{tabular}{|c|c|c|c|}
\hline Linguistic expressions & Exp. 1 & Exp. 2 & Exp. 3 \\
\hline VLI & $(0.05,0.1,0.25)$ & $(0.05,0.1,0.31)$ & $(0.05,0.15,0.29)$ \\
LI & $(0.25,0.3,0.45)$ & $(0.22,0.3,0.47)$ & $(0.24,0.3,0.51)$ \\
I & $(0.45,0.5,0.65)$ & $(0.4,0.5,0.68)$ & $0.5,0.76)$ \\
VI & $(0.65,0.7,0.85)$ & $(0.58,0.7,0.87)$ & $(0.62,0.7,0.87)$ \\
VVI & $(0.85,1,1)$ & $(0.77,1,1)$ & $(0.82,1,1)$ \\
\hline
\end{tabular}

Table 9. Experts' Evaluations of Variables

\begin{tabular}{|c|c|c|c|c|}
\hline Variables & Code & Exp. 1 & Exp. 2 & Exp. 3 \\
\hline Housing condition & $V_{1}$ & VI & I & I \\
Educational status & $V_{2}$ & LI & I & LI \\
Monthly income & $V_{3}$ & VVI & VVI & VVI \\
Number of dependent person & $V_{4}$ & I & I & LI \\
Special vulnerability & $V_{5}$ & VI & I & VLI \\
Food security & $V_{6}$ & I & VI & VI \\
Cooking fuel & $V_{7}$ & I & VLI & LI \\
Internet access & $V_{8}$ & I & LI & I \\
Use of transportation vehicle & $V_{9}$ & VLI & VLI & LI \\
\hline
\end{tabular}

Table 10. Weighted Valued Matrix

\begin{tabular}{|c|c|c|c|c|c|c|}
\hline Code & Exp. 1 & Exp. 2 & Exp. 3 & Aggregated val. & Defuzzy. Val. & Norm. \\
\hline$V_{1}$ & $(0.65,0.7,0.85)$ & $(0.4,0.5,0.68)$ & $(0.42,0.5,0.76)$ & $(0.4,0.57,0.85)$ & 0.60 & 0.13 \\
$V_{2}$ & $(0.25,0.3,0.45)$ & $(0.4,0.5,0.68)$ & $(0.24,0.3,0.51)$ & $(0.24,0.37,0.68)$ & 0.41 & 0.09 \\
$V_{3}$ & $(0.85,1,1)$ & $(0.77,1,1)$ & $(0.82,1,1)$ & $(0.77,1,1)$ & 0.94 & 0.21 \\
$V_{4}$ & $(0.45,0.5,0.65)$ & $(0.4,0.5,0.68)$ & $(0.24,0.3,0.51)$ & $(0.24,0.43,0.68)$ & 0.45 & 0.10 \\
$V_{5}$ & $(0.65,0.7,0.85)$ & $(0.4,0.5,0.68)$ & $(0.05,0.15,0.29)$ & $(0.05,0.45,0.85)$ & 0.45 & 0.10 \\
$V_{6}$ & $(0.45,0.5,0.65)$ & $(0.58,0.7,0.87)$ & $(0.62,0.7,0.87)$ & $(0.45,0.63,0.87)$ & 0.65 & 0.14 \\
$V_{7}$ & $(0.45,0.5,0.65)$ & $(0.05,0.1,0.31)$ & $(0.24,0.3,0.51)$ & $(0.05,0.3,0.65)$ & 0.33 & 0.07 \\
$V_{8}$ & $(0.45,0.5,0.65)$ & $(0.22,0.3,0.47)$ & $(0.42,0.5,0.76)$ & $(0.22,0.43,0.76)$ & 0.46 & 0.10 \\
$V_{9}$ & $(0.05,0.1,0.25)$ & $(0.05,0.1,0.31)$ & $(0.24,0.3,0.51)$ & $(0.05,0.17,0.51)$ & 0.22 & 0.05 \\
\hline
\end{tabular}


Table 11. Poverty Index Components

\begin{tabular}{|c|c|c|c|}
\hline Households & $f_{i}$ & $\xi_{i}$ & $\eta_{i}$ \\
\hline$H_{1}$ & 0.816 & 0.007 & 0.108 \\
$H_{2}$ & 0.894 & 0.006 & 0.020 \\
$H_{3}$ & 0.372 & 0.011 & 0.768 \\
$H_{4}$ & 0.640 & 0.008 & 0.336 \\
$H_{5}$ & 0.254 & 0.012 & 1 \\
\hline
\end{tabular}

Table 12. Household Poverty Index Data

\begin{tabular}{|c|c|c|c|c|c|c|c|c|c|c|c|c|c|c|c|}
\hline $\mathrm{H}_{\mathrm{i}}$ & $\eta_{i}$ & $\mathrm{H}_{\mathrm{i}}$ & $\eta_{i}$ & $\mathrm{H}_{\mathrm{i}}$ & $\eta_{i}$ & $\mathrm{H}_{\mathrm{i}}$ & $\eta_{i}$ & $\mathrm{H}_{\mathrm{i}}$ & $\eta_{i}$ & $\mathrm{H}_{\mathrm{i}}$ & $\eta_{i}$ & $\mathrm{H}_{\mathrm{i}}$ & $\eta_{i}$ & $\mathrm{H}_{\mathrm{i}}$ & $\eta_{i}$ \\
\hline 1 & 0,108 & 16 & 0,292 & 31 & 0,188 & 46 & 0,561 & 61 & 0,006 & 76 & 0,315 & 91 & 0,275 & 106 & 0,232 \\
\hline 2 & 0,020 & 17 & 0,315 & 32 & 0,275 & 47 & 0,232 & 62 & 0,768 & 77 & 0,490 & 92 & 0,294 & 107 & 0,764 \\
\hline 4 & 0,336 & 19 & 0,734 & 34 & 0,532 & 49 & 0,483 & 64 & 1,000 & 79 & 0,516 & 94 & 0,268 & 109 & 0,000 \\
\hline 5 & 1,000 & 20 & 0,516 & 35 & 0,268 & 50 & 0,000 & 65 & 0,354 & 80 & 0,076 & 95 & 0,713 & 110 & 0,434 \\
\hline 6 & 0,354 & 21 & 0,076 & 36 & 0,713 & 51 & 0,434 & 66 & 0,840 & 81 & 0,158 & 96 & 0,243 & 111 & 0,232 \\
\hline 8 & 0,612 & 23 & 0,553 & 38 & 0,488 & 53 & 0,572 & 68 & 0,430 & 83 & 0,168 & 98 & 0,456 & 113 & 0,731 \\
\hline 9 & 0,430 & 24 & 0,168 & 39 & 0,456 & 54 & 0,731 & 69 & 0,435 & 84 & 0,446 & 99 & 0,589 & 114 & 0,023 \\
\hline 10 & 0,435 & 25 & 0,446 & 40 & 0,589 & 55 & 0,023 & 70 & 0,334 & 85 & 0,711 & 100 & 0,332 & 115 & 0,190 \\
\hline 11 & 0,334 & 26 & 0,711 & 41 & 0,332 & 56 & 0,190 & 71 & 0,235 & 86 & 0,347 & 101 & 0,252 & 116 & 0,330 \\
\hline 12 & 0,235 & 27 & 0,347 & 42 & 0,252 & 57 & 0,330 & 72 & 0,275 & 87 & 0,141 & 102 & 0,460 & 117 & 0,191 \\
\hline 13 & 0,275 & 28 & 0,141 & 43 & 0,460 & 58 & 0,191 & 73 & 0,310 & 88 & 0,453 & 103 & 0,655 & 118 & 0,537 \\
\hline 14 & 0,310 & 29 & 0,453 & 44 & 0,655 & 59 & 0,537 & 74 & 0,423 & 89 & 0,461 & 104 & 0,600 & 119 & 0,553 \\
\hline
\end{tabular}

In this study conducted a household poverty survey by using the method proposed by [7]. The calculation steps of the final poverty index are as follows:

i. The weighted average $\left(f_{i}\right)$ of each household was calculated by using the relevant household data. This value is an indicator which represents the level of poverty. In [7], the proposed average value is calculated differently. $f_{i}$ overhauled in this study.

ii. A set of poor households was formed by using the formula $\xi_{i}=\frac{e^{-f_{i}}}{\sum_{i=1}^{n} e^{-f_{i}}}$.

iii. Finally, the poverty index value is calculated using the formula of $\eta_{i}=\frac{\xi_{i}-\min \left(\xi_{i}\right)}{\max \left(\xi_{i}\right)-\min \left(\xi_{i}\right)}$.

The $\eta_{i}$ value is a metric calculated at the interval $[0,1]$ and indicating that poverty decreases as the value approaches " 1 ". The components in Table 11 were calculated using all household data. The index value of the data set of the fifth household with 120 observations was found to be the highest. According to the calculated index, it is possible to rank households by poverty level. The index, which is between 0 and 1 , is classified as five different categories. Index value determined the households as "Totally poor" (TP) up to 0.18 , "poor" (P) up to 0.38 , "moderately poor" (MP) up to 0.58 , "not poor" (NP) up to 0.78 and "totally not poor" (TNP) up to 1 . The classification can be made according to the highest weighted variable or it can be possible to specify different criteria. According to the classification made, 17 households (14\%) are very poor, 42 households (35\%) are poor, 37 households (31\%) are moderate, 20 households (17\%) are not poor and 4 households not poor at all.

\section{Discussion and Recommendation}

Poverty and income inequality are seen as a very important problem, especially in undeveloped or developing countries. At this point, it is an important debate issue to determine the source of problems, to measure poverty or income inequality correctly. Factors affecting poverty should be addressed in all dimensions and it is necessary to determine the points at which there are deficiencies and take the necessary precautions. This study shows that it is not enough to measure poverty with a one-dimensional measurement methodology only on the basis of the income. Many factors affecting poverty have been taken into account, their impacts examined and remarkable results revealed. It has been determined based on expert evaluations that a significant part of the identified variables affect poverty at a level close to the income variable. After identifying that poverty should be handled in a multidimensional manner, it has been tried to determine which point of Bayburt is in poverty. As a result of the analysis, about $50 \%$ of the Bayburt province has been identified as poor and very poor. In addition, it should be said that this ratio may be higher if the rules of classification are stricter. Bayburt province has been in a position to emigrate for many years due to its geographical location and limited employment opportunities. For this reason, the population has decreased continuously. Limited employment opportunities have caused the qualified individuals to go out of the province and the people living in the rural areas to fall down. Although geographically suitable for the structure of agriculture and animal husbandry, unfortunately it is very limited. Therefore, the city is backward from the economic and social condition. It is possible to arrange the reasons that explain the poverty 
outcomes obtained in this study.

Fuzzy logic is frequently used in the measurement of poverty. The modeling of uncertainty in human thought using linguistic expressions and fuzzy membership functions and its numerical representation enables the use of fuzzy logic to move quickly from the science to the social sciences. From this point of view, it was thought that to be useful the expert evaluations in measuring the poverty. The uncertainty of poverty has been tried to be included the calculations in this way. This study is important to perform the successful application of fuzzy logic for poverty measurement and to uncover the unforeseen problems that may be encountered during application. For further studies, a household survey and poverty measurement across the country could be considered as a widespread effect of the study. In addition, the performances of different membership function types can also be compared. It may be possible to construct and compare categories of poverty by setting different criteria at the decision stage.

\section{REFERENCES}

[1] S. Alkire and M. E. Santos, “Acute Multidimensional Poverty: A New Index for Developing Countries,” New York, 11, 2010.

[2] T. Bayramoğlu and S. Yaprakl1, "Küreselleşmenin Öteki yüzü: Yoksulluk ve Gelir Dağılımı Adaletsizliği," in 2. International Congress on Applied Sciences, Poverty, Migration \& Employment, 2016.

[3] G. Datt, "Computational Tools for Poverty Measurement and Analysis,” USA, 50, 1998.

[4] Ş. Çalışkan, "Türkiye'de Gelir Eşitsizliği ve Yoksulluk," Sos. Siyaset Konf. Derg., vol. 59, no. 2, pp. 89-132, 2010.

[5] A. Sen, "Poverty: An Ordinal Approach to Measurement," Econometrica, vol. 44, no. 2, pp. 219-231, 1976.

[6] A. J. M. Hagenaars and B. M. S. van Praag, "A Synthesis of Poverty Line Definitions,” Rev. Income Wealth, vol. 31, no. 2, pp. 139-154, Jun. 1985.

[7] A. Chatterjee, S. Mukherjee, and S. Kar, "Poverty Level of Households: A Multidimensional Approach Based on Fuzzy Mathematics,” Fuzzy Inf. Eng., vol. 6, no. 4, pp. 463-487, 2014.

[8] A. Cerioli and S. Zani, "A Fuzzy Approach To The Measurement Of Poverty," in Income and Wealth Distribution, Inequality and Poverty: Proceedings of the Second International Conference on Income Distribution by Size: Generation, Distribution, Measurement and Applications, Held at the University of Pavia, Italy, September 28--30, 19, C. Dagum and M. Zenga, Eds. Berlin, Heidelberg: Springer Berlin Heidelberg, 1990, pp. 272-284.

[9] A. Uzun, "Yoksulluk olgusu ve Dünya Bankasi,” CÜ Iktis. ve idari Bilim. Derg., vol. 4, no. 2, pp. 155-173, 2001.

[10] D. Gürses, “Türkiye’de yoksulluk ve yoksullukla mücadele politikaları,” Balıkesir Üniversitesi Sos. Bilim. Enstitüsü Derg., vol. 17, no. 1, pp. 59-74, 2007.
[11] Ö. A. Kızılgöl and C.. Demir, "Türkiye' de Yoksulluğun Boyutuna İlişkin Ekonometrik Analizler," Bus. Econ. Res. J., vol. 1, no. 1, pp. 21-32, 2010.

[12] S. Alkire and J. Foster, "Counting and multidimensional poverty measurement,” J. Public Econ., vol. 95, no. 7-8, pp. 476-487, 2011.

[13] M. Bilen and M. Çalışır, “Türkiye'de Yoksulluk Tuzağının Politik Belirleyicileri,” Akad. Incelemeler Derg., vol. 8, no. 1, pp. 321-345, 2013.

[14] C. T. Whelan, B. Nolan, and B. Maître, "Multidimensional poverty measurement in Europe: An application of the adjusted headcount approach,” J. Eur. Soc. Policy, vol. 24, no. 2, pp. 183-197, Apr. 2014.

[15] L. a. Zadeh, “Fuzzy sets,” Inf. Control, vol. 8, no. 3, pp. 338353, 1965.

[16] M. Qizilbash, "Philosophical Accounts of Vagueness, Fuzzy Poverty Measures and Multidimensionality,” in Fuzzy Set Approach to Multidimensional Poverty Measurement, A. Lemmi and G. Betti, Eds. Boston, MA: Springer US, 2006, pp. 9-28.

[17] E. Chiappero-Martinetti, “A New Approach to Evaluation of Well-Being and Poverty by Fuzzy Set Theory,” G. degli Econ. e Ann. di Econ., vol. 53, pp. 367-388, 1994.

[18] E. Chiappero-Martinetti, "A multidimensional assessment of well-being based on Sen's functioning approach,” Riv. Int. Sci. Sociali, vol. 108, pp. 207-236, 2004.

[19] J. Deutsch and J. Silber, "Measuring Multidimensional Poverty: An Empirical Comparison of Various Approaches," Rev. Income Wealth, vol. 51, no. 1, pp. 145-174, Mar. 2005.

[20] L. Abdullah and A. O. M. Tap, "Fuzzy human development index: A numerical example of Southeast Asian countries," Int J. Ecol. Econ. Stat., vol. 14, no. P09, pp. 104-113, 2009.

[21] M. L. Abdullah and A. O. M. Tap, "Quality of life index of three selected states in the Peninsular Malaysia: Fuzzy sets approach,” Int. J. Ecol. Econ. Stat., vol. 11, no. S08, pp. 90-99, 2009.

[22] M. A. Lazim and M. T. Abu Osman, “A New Malaysian Quality of Life Index Based on Fuzzy Sets and Hierarchical Needs,” Soc. Indic. Res., vol. 94, no. 3, p. 499, 2009.

[23] H. Pabuçcu and T. Y. Ayan, "The Development of an Alternative Method for the Sovereign Credit Rating System Based on Adaptive Neuro-Fuzzy Inference System,” Am. J. Oper. Res., vol. 7, no. 1, pp. 41-55, 2017.

[24] H. Pabuçcu, "Uyarlanabilir Sinirsel Bulanık Çıkarım Sistemi Tabanlı Alternatif Bir Kredi Derecelendirme Yönteminin Geliştirilmesi," Karadeniz Teknik Üniversitesi SBEYayınlanmamış Doktora Tezi, 2015.

[25] C. C. C. Lee, "Fuzzy logic in control systems: fuzzy logic controller. II,” IEEE Trans. Syst. Man. Cybern., vol. 20, no. 2, pp. 404-418, 1990.

[26] W. Van Leekwijck and E. E. Kerre, "Defuzzification: criteria and classification,” Fuzzy Sets Syst., vol. 108, no. 2, pp. 159178, 1999.

[27] H. C. Chang, "An application of fuzzy sets theory to the EOQ model with imperfect quality items," Comput. Oper. Res., vol. 31, no. 12, pp. 2079-2092, 2004. 